\title{
Making sense of coronavirus news maps: A multiple sorting approach
}

\author{
Johanna Meyer $^{\mathrm{a}, *}$, Danae Stanton Fraser ${ }^{\mathrm{a}}$, Julie Barnett ${ }^{\mathrm{a}}$ \\ a University of Bath, jpm87@bath.ac.uk, Danae Stanton Fraser, D.StantonFraser@bath.ac.uk, Julie Barnett, \\ J.C.Barnett@bath.ac.uk \\ * Corresponding author
}

Keywords: news maps, map interpretation, card sorting, coronavirus maps, COVID-19 map

\begin{abstract}
:
The news is a medium through which people of all walks of life interact with maps on a regular basis. The coverage of the current coronavirus pandemic provides a unique opportunity to study the reception of public health news maps. This paper outlines the development of a study exploring the processes involved in making sense of everyday maps.
\end{abstract}

News maps have been argued to carry political meaning (Batuman, 2010; Churchill \& Stege, 2006; Kosonen, 1999; Vujakovic, 1999, 2002), downplay environmental problems (Lyytimäki, 2020), and guide public risk perception in emergent health crises (Welhausen, 2017). In a prior study we are exploring the different representations of coronavirus in UK news maps during the early stages of the pandemic. These examples not only position news maps as rhetoric devices capable of presenting different arguments but also point to the importance of considering map interpretation as a process that is embedded in map users' understanding of the world.

Individuals' prior beliefs and experiences having been shown to influence the interpretation of risk maps (Severtson \& Vatovec, 2012) and infographics (Kennedy et al., 2016), this study is interested in how news map users draw on their prior understanding of the mapped topic and on their understanding of the map as a means of communication when engaging with news maps relating to a public health emergency.

In the current study using the maps identified in our previous work, a multiple card sorting procedure was used to explore the conceptual frameworks news maps are approached with (Canter et al., 1985). In an interview setting with a whiteboard used for the sorting task, participants were asked to sort a set of 15 cards (maps) into groups against any criterion of their choice (free sorts) and responding to probes (semi-structured sorts). The probes were aimed at encouraging sorts that would tap into participants' perceptions of the maps' form as well as their content, such as asking about the perceived credibility of the maps. Participants were encouraged to talk through their sorting decisions and to label the resultant categories. Multidimensional scaling was applied to the sorts within and across maps, within groups and within participants, with cluster graphs interpreted in the light of the qualitative data obtained from participants' sorting decisions. This approach takes into account both the recurrence of map (dis)similarity judgements across and within users and users' justifications for these judgements to explore the conceptual frameworks against which the maps are interpreted (Canter et al., 1985).

The stimuli were taken from our 1,256-map corpus of UK news maps relating to coronavirus during the early stages of the public health crisis. Fifteen maps were selected to systematically reflect different framings of coronavirus and to represent different map designs and news sources (left and right leaning, tabloid and broadsheet news outlets).

In order to capture a readership $(n=45)$ likely to be diverse in their perception of the mapped topic and in their prior exposure to maps of different styles, participants were recruited along the dimensions of self-identified political orientation (left, right, centre/unaffiliated) and style of their primary news source (broadsheet, tabloid, not using mainstream news). As the stimuli maps were taken from UK news outlets, the sample was restricted to UK residents.

Data collection is ongoing. The study will provide empirical evidence on the conceptual frameworks users draw on when interpreting public health related news maps. It will provide insights into how map users embed a news map in their prior understanding of a topic and in their understanding of a map as a visualisation. It may further provide evidence on news map users' expectations about map design and content. The findings may have implications for map design beyond news maps by suggesting factors related to users' prior understanding that may interact with intended map communication. 


\section{References}

Batuman, B. (2010). The shape of the nation: Visual production of nationalism through maps in Turkey. Political Geography, 29(4), 220-234. https://doi.org/10.1016/j.polgeo.2010.05.002

Canter, D., Brown, J., \& Groat, L. (1985). A multiple sorting procedure for studying conceptual systems. In Brenner, M., Brown, J., \& Canter, D. (Eds.), The Research Interview: Uses and Approaches (pp. 79-114). Academic Press. https://www.researchgate.net/profile/David-

Canter/publication/259779646_A_Multiple_Sorting_Procedure_for_Studying_Conceptual_Systems/links/0a85e52dec c9027a92000000/A-Multiple-Sorting-Procedure-for-Studying-Conceptual-Systems.pdf

Churchill, R. R., \& Stege, E. H. (2006). From Afghanistan to Iraq in media maps: Journalistic construction of geographic knowledge. Cartographic Perspectives, 54, 55-68. https://doi.org/10.14714/CP54.346

Kennedy, H., Hill, R. L., Allen, W., \& Kirk, A. (2016). Engaging with (big) data visualizations: Factors that affect engagement and resulting new definitions of effectiveness. First Monday, 21(11). https://doi.org/10.5210/fm.v21i11.6389

Kosonen, K. (1999). Maps, newspapers and nationalism: The Finnish historical experience. GeoJournal, 48(2), 91-100. https://doi.org/10.1023/A:1007038819154

Lyytimäki, J. (2020). Maps of light pollution in odd places: Are night time satellite pictures making us to forget natural darkness? International Journal of Sustainable Lighting, 22(1), 1-11. https://doi.org/10.26607/ijsl.v22i1.96

Severtson, D. J. \& Vatovec, C. (2012). The theory-based influence of map features on risk beliefs: Self-reports of what is seen and understood for maps depicting an environmental health hazard. Journal of Health Communication, 17(7), 836-856. https://doi.org/10.1080/10810730.2011.650933

Vujakovic, P. (1999). 'A new map is unrolling before us': Cartography in news media representations of post-cold War Europe. The Cartographic Journal, 36(1), 43-57. https://doi.org/10.1179/caj.1999.36.1.43

Vujakovic, P. (2002). Mapping the war zone: cartography, geopolitics and security discourse in the UK press. Journalism Studies, 3(2), 187-202. https://doi.org/10.1080/14616700220129964

Welhausen, C. A. (2017). Visualizing science: Using grounded theory to critically evaluate data visualizations. In Yu, H. \& Northcut, K. M. (Eds.), Scientific Communication: Practices, Theories, and Pedagogies (pp. 82-106). Routledge. https://doi.org/10.4324/9781315160191-5 